\title{
Interação entre SARS-CoV-2 e o sistema Renina Angiotensina
}

\author{
Interaction between SARS-CoV-2 and \\ the Renin Angiotensin system
}

\section{Jefferson Petto ${ }^{1}$ (1) \\ Pedro Henrique Silva Santos ${ }^{2}$ (1) \\ Luana Farias Souza dos Santos ${ }^{3}$ (1) \\ Deise Santos da Silva Sena ${ }^{4}$ (1) \\ Marvyn de Santana do Sacramento ${ }^{5}$ (1)}

\begin{abstract}
${ }^{1}$ Autor para correspondência. Centro Universitário Social da Bahia, Actus Cordios Serviço de Reabilitação Cardiovascular, Escola Bahiana de Medicina e Saúde Pública (Salvador). Bahia, Brasil. gfpecba@bol.com.br

${ }^{2}$ Fundação Estatal de Saúde da Família/Fundação Oswaldo Cruz (Salvador). Bahia, Brasil. pedrossantos121@gmail.com

3,4Universidade Tecnologia e Ciências de Salvador, Escola Bahiana de Medicina e Saúde Pública (Salvador). Bahia, Brasil. luannafss21@gmail.com, deisesena@live.com

${ }^{5}$ Centro Universitário Social da Bahia, Actus Cordios Serviço de Reabilitação Cardiovascular (Salvador). Bahia, Brasil. marvynsantana@gmail.com
\end{abstract}

PALAVRAS-CHAVE: Inflamação. Sistema Nervoso Simpático. Contaminação. COVID-19. Infecção por Coronavirus.

KEYWORDS: Inflammation. Sympathetic Nervous System. Contamination. COVID-19. Coronavirus Infections.

\section{Introdução}

A COVID-19 ou SARS-CoV-2, como o denominou o Grupo de Estudos de Coronavírus do Comitê Internacional de Taxonomia de Vírus ${ }^{1}$, é uma doença causada por betacoronavírus do mesmo subgênero da síndrome da insuficiência respiratória aguda grave (SARS)2. Em Agosto de 2020, a pandemia alastrou-se para mais de 188 nações, causando mais de 21,4 milhões infectados e mais 771.000 vítimas fatais no mundo 3 . A Organização Mundial de Saúde traz dados atualizados, confirmando mais de 47,9 milhões casos de SARS-CoV-2 e 1.290 .653 mortes até 15 de novembro de $2020^{4}$.

A SARS-CoV-2 é uma enfermidade espectral, cujo quadro clínico dos infectados pode variar do assintomático até a morte. Na ausência de uma classificação baseada nos sintomas, propomos aqui uma classificação clínica dividida em cinco estágios, descrita no Quadro 1. 


\begin{tabular}{|l|l|}
\hline Estágios & Característica Clínica \\
\hline I & Contaminado, mas assintomático. \\
\hline II & $\begin{array}{l}\text { Com sintomas gripais leves: febre, inflamação, dor de garganta, dores nas articulações, anosmia, } \\
\text { disgeusia e tosse seca. Necessita apenas de cuidados para gripe comum. Corresponde a 80\% dos } \\
\text { casos. }\end{array}$ \\
\hline III & $\begin{array}{l}\text { Com sintomas gripais associados a desconforto respiratório agudo ou síndrome respiratória aguda, } \\
\text { apresentando ou não complicação cardíaca e/ou renal, necessitando de cuidados de saúde de média } \\
\text { complexidade. }\end{array}$ \\
\hline IV & $\begin{array}{l}\text { Com sintomas gripais, síndrome respiratória aguda associada ou não a complicações cardíacas e/ou } \\
\text { a insuficiência renal aguda, com necessidade de cuidados de saúde de alta complexidade. }\end{array}$ \\
\hline V & Complicações cardiorrespiratórias que culminam com morte. Representa entre 2 a $4 \%$ dos casos. \\
\hline
\end{tabular}

A mortalidade ocasionada pela SARS-CoV-2 está associada aos seguintes fatores: Diabetes Mellitus, Hipertensão Arterial Sistêmica (HAS), Doença Arterial Coronariana e idade acima de 70 anos (único fator não modificável)5. 0 processo inflamatório apresenta também associação com a mortalidade após infecção pela SARS-CoV-2. Marcadores inflamatórios elevados, como Proteína C Reativa e Interleucina-6, foram preditores de pior prognóstico.

De acordo com a fisiopatologia descrita até então, a SARS-CoV-2 penetra nas células humanas pelos mesmos receptores da Enzima Conversora de Angiotensina 2 (ECA 2). A ECA 2 é uma enzima constituinte do Sistema ReninaAngiotensina (SRA), sendo expressa principalmente no endotélio arterial das coronárias e vasos intra-renais, no tecido epitelial pulmonar e enterócitos ${ }^{6-7}$. O entendimento da interação da SARS-CoV-2 com o SRA é de grande importância para atuação dos mais diferentes profissionais de saúde. Portanto, neste artigo objetivamos descrever com profundidade o SRA e posteriormente a interação entre a SARS-CoV-2 com esse sistema. Dessa forma, procuramos elucidar algumas questões ainda pouco compreendidas sobre a enfermidade e levantamos algumas hipóteses baseadas no contexto exposto que poderão nortear futuras investigações.

\section{Sistema Renina Angiotensina}

O SRA pode ser dividido em sistêmico e tecidual. A produção de angiotensinas que agem nos diferentes tecidos corporais (SRA sistêmico) tem como protagonistas o fígado, os rins e o endotélio vascular arterial, tratando-se de um sistema hormonal endócrino. Já o SRA tecidual age de forma autócrina e parácrina. Todos os constituintes do SRA são produzidos de forma local no coração, cérebro, vasos sanguíneos arteriais (endotélio), rins, glândulas adrenais, órgãos reprodutores, pâncreas e tecido adiposo ${ }^{7-9}$. Como os SRA sistêmico e tecidual são homólogos, iremos descrever especificamente a via sistêmica, nos reportando quando necessário, à via tecidual.

As principais moléculas constituintes desse sistema são: o angiotensinogênio, as angiotensinas I, II, III, IV e I-VII, as enzimas conversoras de angiotensina 1 e 2 (ECA 1 e 2) e os receptores de angiotensina 1, 2, 4 e 1-7 (AT1, AT2, AT4 e AT1-7).

\section{Angiotensinogênio e Renina}

O SRA se inicia com a liberação do angiotensinogênio na corrente sanguínea. Produzido de forma constante no fígado, o angiotensinogênio é uma glicoproteína inativa que ao ser clivado pode originar diretamente a Angiotensina I (Angio I) ou a Angiotensina II (Angio II). A reposição de estrogênio de forma biológica ou sintética e glicocorticoides elevam sua produção hepática ${ }^{10}$. Algumas são as enzimas que participam da clivação do Angiotensinogênio, como a Tonina, a Catepsina G (ambas com função aumentada em processos inflamatórios) e a Renina. Contudo, o papel de protagonista majoritária nesse processo é da renina ${ }^{11}$. 
A renina é uma enzima produzida nas células justaglomerulares dos rins e sua elevação ocorre frente à sinalização de diminuição do fluxo sanguíneo renal ou por estímulo simpático ${ }^{10}$. Como o SRA é um dos principais sistemas reguladores da pressão arterial (PA) a médio (minutos) e longo prazo (dias, meses), ele normalmente é ativado frente à diminuição da PA. A baixa pressão nas arteríolas aferentes renais; o baixo fluxo sanguíneo na mácula densa dos túbulos renais distais; e o estímulo neural simpático decorrente de queda da PA sobre as células justaglomerulares dos rins, são todos mecanismos que aumentam a produção de renina. Como a produção de angiotensinogênio pelo fígado é relativamente constante, quem determina o incremento da atividade do SRA é a produção de renina ${ }^{11}$. É importante entender que esse é um sistema regulador da PA, portanto, ele atua de forma constante, elevando ou diminuindo sua atividade vasoconstritora e vasodilatadora por retroalimentação negativa.

\section{O Papel da Inflamação}

A inflamação é um estímulo potente para a produção de renina ${ }^{12}$. Estudos apontam que a inflamação eleva a ativação do sistema nervoso autônomo simpático o que, por sua vez, estimula receptores ß-adrenérgicos tipo 1 das células justaglomerulares renais, incrementando a expressão de renina e a consequente atividade do SRA $10,12,13$. Portanto, qualquer fator que estimule a inflamação, por efeito, eleva a atividade do SRA.

Observem que o aumento da descarga autonômica simpática eleva tanto a produção de renina como a própria inflamação. Esse é, portanto, um mecanismo de retroalimentação positiva, pois, a maior produção de renina leva a maior produção de Angio II, o que, por sua vez, ao se ligar a receptores AT1, pode elevar a atividade inflamatória em diversos tecidos, incluindo pulmões, coração e a própria atividade nervosa central simpática, que novamente favorece a produção de renina e a inflamação. Ademais, é significante reportar ao conhecimento de que em processos inflamatórios, crônicos ou agudos, não só a renina, mas também outras enzimas, a tonina e a catepsina
$\mathrm{G}$, anteriormente mencionadas, aumentam sua atividade favorecendo a transformação do angiotensinogênio em Angio I e Angio II. Mais um fator que ratifica a intensificação do SRA frente à inflamaçãoํㅗ.

\section{Angiotensina I, Enzima Conversora de Angiotensina 1 e Angiotensina I-VII}

Na continuidade do SRA, após a formação da Angio I, que é uma molécula essencialmente inativa, ocorre a clivagem dessa em Angio II pela ação da ECA 1. A ECA 1 é produzida no endotélio vascular arterial de todos os tecidos, sendo identificada maior produção e atividade dessa molécula no endotélio vascular arterial pulmonar ${ }^{2}$. Além de clivar a Angio I para formar Angio II e de clivar a Angio I-VII para formar Angio I-V, a ECA 1 participa da degradação da bradicinina em compostos inativos, os BK(1-7).

A bradicinina é uma potente molécula vasodilatadora, broncodilatadora e natriurética, produzida no endotélio vascular arterial. Portanto, a elevação da produção da ECA 1 favorece o eixo de subida da PA controlado pelo SRA, pois, ao se ligar a receptores AT1 a Angio II desencadeia vasoconstrição direta dos vasos arteriais e indireta via produção de vasopressina no hipotálamo, além de inativar um potente vasodilatador - a bradicinina ${ }^{11}$.

A Angio I é uma molécula inativa que além de ser a precursora da Angio II é precursora também da Angio I-VII e da Angio I-IX. A Prolil Endopepitase (PEP) e a Endopeptase Neutra (NEP) são as enzimas que atuam na reação de transformação da Angio I em Angio I-VII e a ECA 2 na da Angio I em Angio I-IX. Enquanto, a Angio I-IX é uma molécula biologicamente inativa, a Angio I-VII desencadeia várias ações importantes, a maioria delas contrárias às da Angio II, quando essa se liga aos receptores AT19. A Figura 1 mostra que a Angio I-VII pode, pela ação da ECA 1 , se transformar em Angio I-V, molécula até então reconhecida como inativa. A Angio I-IX pela ação da ECA 1 ou da NEP pode se transformar em Angio I-VII. A Figura 2 sumariza as ações da Angio I-VII ao se ligar ao receptor 1-7(Mas) 
Figura 1. Resumo das interações presentes no sistema renina-angiotensina

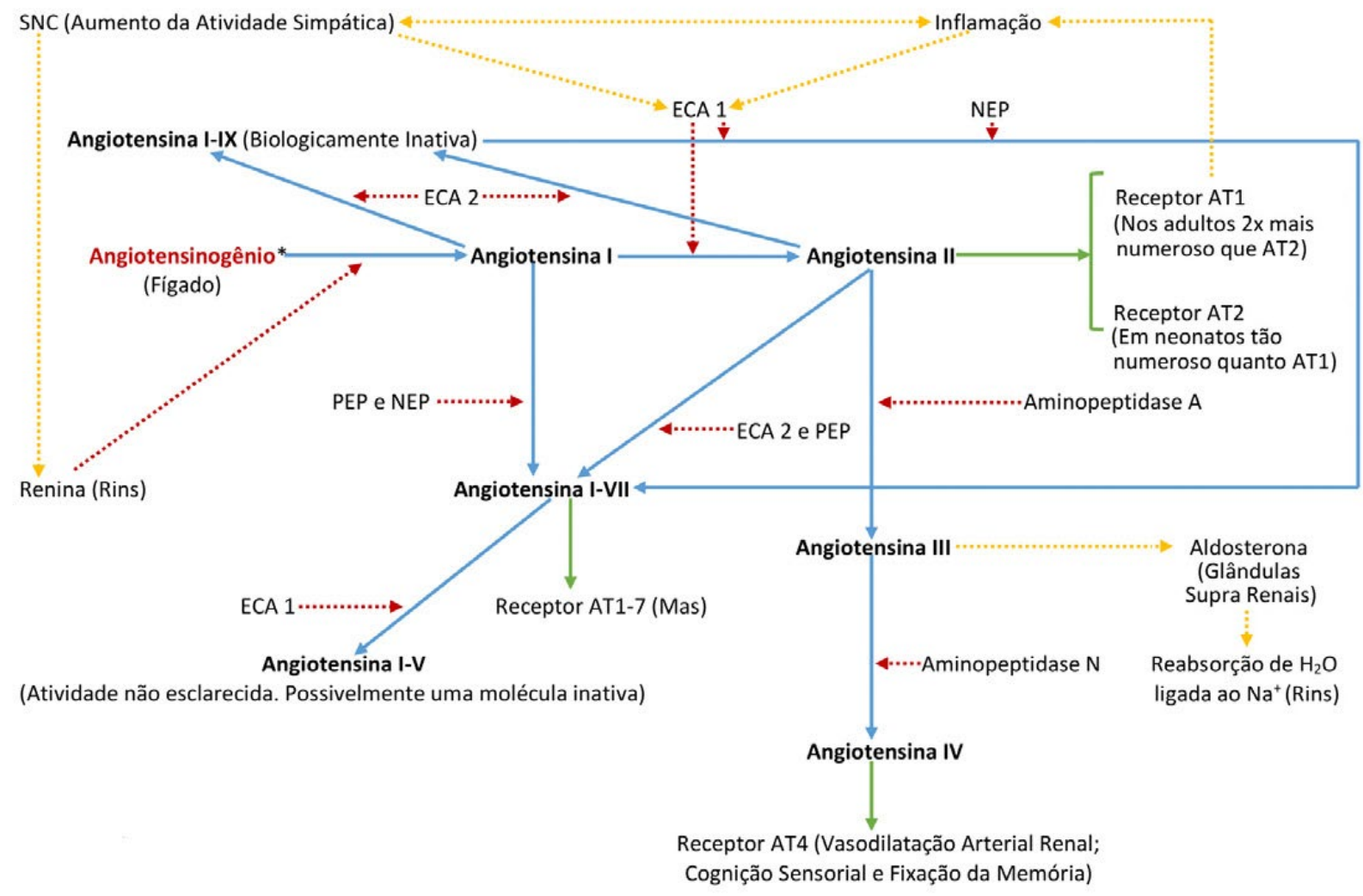

Linha sólida azul - indica a direção da transformação bioquímica. Linha Sólida Verde - Indica a ligação da molécula com seu receptor. Linha tracejada vermelha indica a transformação pela enzima. Linha tracejada laranja - Indica estímulo de produção ou elevação do fenômeno. ACE 1 - Enzima Conversora de Angiotensina (Somática, produzida no endotélio vascular, principalmente nos pulmões). ACE 2 - Enzima Conversora de Angiotensina (Germinal) (produzida no endotélio epicárdico e nos vasos intrarrenais intra-renais). PEP - prolil endopeptidase. NEP - endopeptidase neutra. * - Início do Sistema Renina-Angiotensina.

Figura 2. Mecanismos de ação das angiotensinas II e I-VI em diferentes receptores

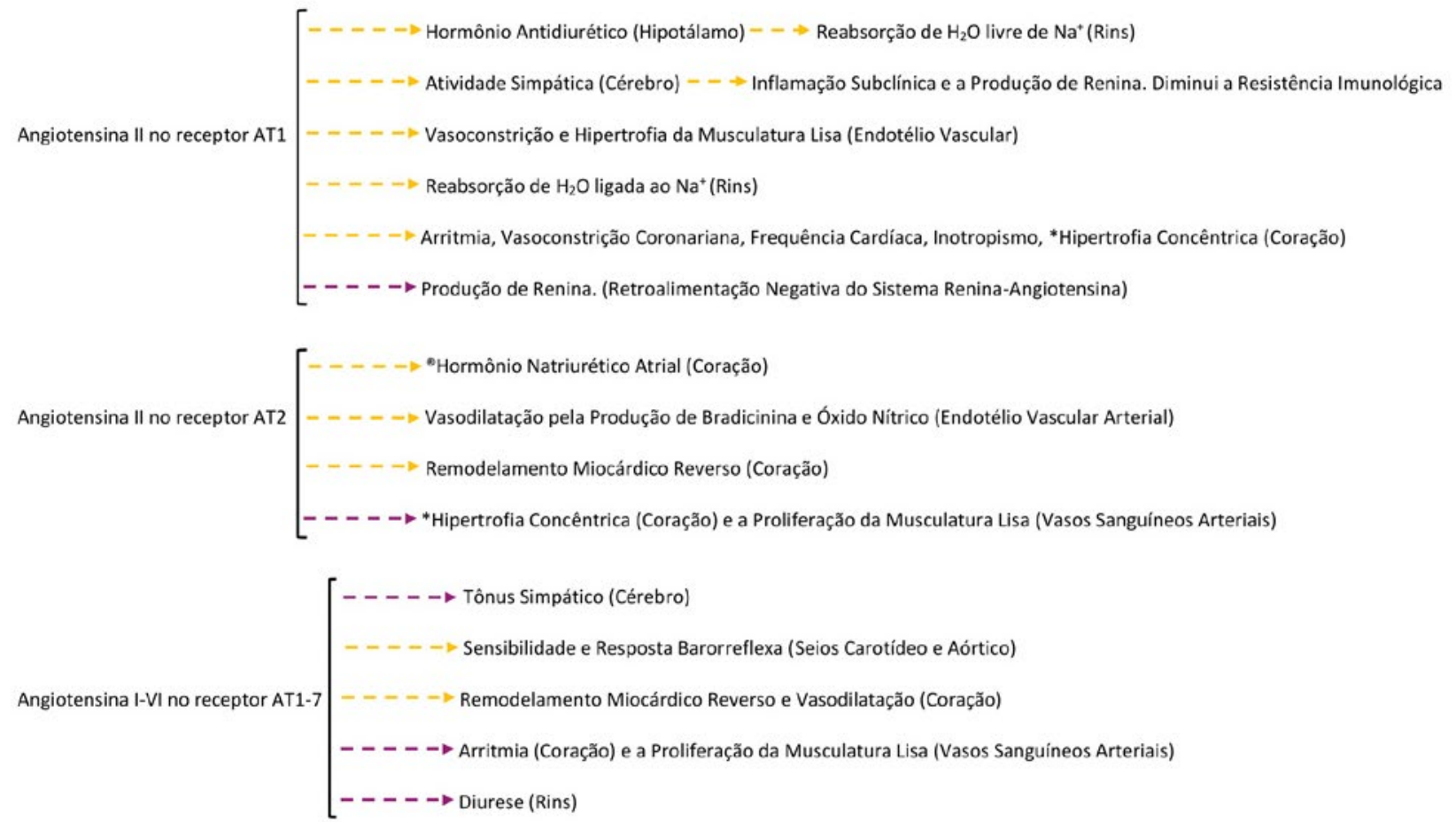

Linha tracejada laranja - indica o estímulo ou aumento do fenômeno. Linha tracejada roxa - indica inibição do fenômeno. ® Hormônio Natriurético Atrial - Atua nos rins estimulando a natriurese. * - Efeitos Crônicos Essenciais 
Dentre as recentes descobertas do SRA, está a de que a Angio I-VII estimula a expressão e atividade da SERCA 2 cardíaca, proteína localizada na membrana do retículo sarcoplasmático que faz a receptação de cálcio para a cisterna terminal, beneficiando o inotropismo cardíaco ${ }^{14}$. Existem ainda as repercussões da Angio I-VII sobre os órgãos reprodutores. Em humanos, foi visto que a ausência da ação da Angio I-VII se expressa no homem, gerando infertilidade, e em muIheres, prejudicando a foliculogênese e a ovulação ${ }^{10}$.

\section{Enzima Conversora de Angiotensina 2}

A ECA 2, também denominada de ECA germinal, assim chamada por ter sido primeiramente observada em células testiculares, guarda $42 \%$ de homologia estrutural com a ECA 1 (somática). Embora, o Ácido Ribonucleico-mensageiro (RNAm) da ECA 2 seja encontrado em quase todos os tecidos corporais, sabemos que ela é produzida especialmente no endotélio arterial das coronárias e vasos intra-renais, no tecido epitelial pulmonar e enterócitos. Ademais, é produzida por células cardíacas, renais, testiculares e musculares lisas ${ }^{6}$. As ações da ECA 2 estão sendo cada vez mais desvendadas pela ciência. Num estudo conduzido por Crackower et al. $\frac{15}{}$, constatou-se que a deleção do gene que codifica a ECA 2 em camundongos provocou grave disfunção contrátil cardíaca. Sabemos que a ECA 2 não somente atua sobre a Angio I como atua principalmente sobre a Angio II. A ECA 2 e a PEP podem catalisar a reação que cliva a Angio II em Angio I-VII. Ainda, a ECA 2 promove a reação que transforma Angio II em Angio I-IX. Também, é de grande interesse destacar que os inibidores de ECA 1 como o captopril e o lisinopril, que comumente são utilizados por indivíduos hipertensos, não inibem a ação da ECA $2^{16}$. Nesse contexto, notem que opostamente à ECA 1, a ECA 2 beneficia a balança vasodilatadora do SRA, já que favorece a transformação da Angio II (potencialmente vasoconstritora e retentora de $\mathrm{H}_{2} \mathrm{O}$ ) em Angio I-VII (vasodilatadora).

Os fatores que levam a uma ou outra reação no SRA ainda não estão elucidados pela literatura, mas, em condições fisiológicas esse é um sistema que se autorregula para manter em níveis aceitáveis a PA. Mediante a necessidade corporal, fatores neurohumorais ou bioquímicos locais favorecem uma ou outra reação. A transformação da Angio II em Angio I-VII favorece a vasodilatação, a diminuição do tônus simpático e o remodelamento miocárdico reverso.
Por outro lado, a Angio II, ao se ligar a receptores AT1, favorece justamente o contrário - vasoconstrição, aumento do tônus simpático e o remodelamento miocárdico?.

\section{Angiotensina II, III e IV}

A Angio II é a molécula central do SRA. É a mais ativa dentre as angiotensinas, podendo seguir cinco caminhos que levam a efeitos distintos, são eles: conversão em Angio I-VII; conversão em Angio I-IX; conversão em Angio III; ligação a receptores AT1; ligação a receptores AT2. Como já foram descritas as conversões da Angio II em Angio I-VII e Angio I-IX, nesta parte do texto, nos ateremos à ação da Angio III e às ações promovidas pela ligação da Angio II a seus receptores AT1 e AT2.

A conversão de Angio II em Angio III é mediada pela enzima Aminopepitidase A. A Angio III, por sua vez, pode passar por mais uma ação enzimática (Aminopeptidase $\mathrm{N}$ ) e se transformar em Angio IV ou se ligar a receptores AT1, localizados nas glândulas suprarrenais e assim estimular a produção de Aldosterona. A Aldosterona produzida pelas suprarrenais atua principalmente nos rins aumentando a reabsorção de $\mathrm{Na}+$ ligado a $\mathrm{H}_{2} \mathrm{O}$ e eliminação de $\mathrm{K}+$. Essa ação favorece a elevação da PA pelo aumento do volume sanguíneo. Importa relatar que ainda não existem evidências consistentes sobre a existência de um receptor AT3 específico para Angio III․

A Angio IV se liga a receptores AT4 localizados principalmente nas artérias renais e cérebro, sendo encontrado também, em menor expressão, no coração, musculatura lisa dos vasos sanguíneos arteriais e glândulas adrenais ${ }^{17}$. A Angio IV, ao se ligar a seu receptor AT4, promove especialmente vasodilatação arterial renal e estímulo à fixação da memória e cognição sensorial e motora, por estimular a produção de Dopamina nos gânglios estriados do encéfalo? Vale ressaltar que a distribuição cerebral dos receptores AT4 é distinta da dos receptores AT1 e AT2. O efeito da Angio IV sobre o sistema nervoso central é reforçado por pesquisas que provocaram inibição dos receptores AT4, observando perda da memória espacial em ratos ${ }^{9}$. Tais estudos apontam que a inibição da Angio IV pode estar ligada ao Alzheimer, convulsões e à doença de Parkinson?. As pesquisas sobre a Angio IV têm crescido, tanto de sua ação sobre o sistema nervoso central como de sua ação tecidual. 
Possivelmente, nos próximos anos, novidades interessantes surjam, como a de que a Angio IV pode se ligar a receptores AT1 dos vasos sanguíneos e provocar vasoconstrição arterial $\frac{18}{2}$. Achados como esse demonstram a complexidade do SRA e a multifacetada relação entre seus componentes.

\section{Angiotensina II e os Receptores AT1 e AT2}

As principais ações da Angio Il ao se ligar aos receptores AT1 e AT2 estão sumarizadas na Figura 2. O maior volume de publicações sobre o SRA é justamente sobre os efeitos da Angio II ao se ligar ao receptor AT1, correspondendo a $60 \%$ das publicações sobre o assunto?. "Em ratos adultos, existe predominância numa relação aproximada de 1,9 receptor AT1 para cada receptor AT2, como observado em células cardíacas no estudo de Tadevosyan et al. ${ }^{19}$.

Os receptores AT1 e AT2 são encontrados praticamente em todos os tecidos corporais. No entanto, sabemos que existem dois subtipos do receptor AT1 (AT1a e AT1b) com 95\% de homologia sequencial de aminoácidos sendo funcionalmente idênticos. O receptor AT1a é expresso principalmente no coração, cérebro e vasos sanguíneos, enquanto que o AT1b apresenta localização limitada a tecidos endócrinos, como as glândulas adrenal e hipófise ${ }^{20}$.

De todas as ações do SRA sistêmico, as que geram implicações sobre o sistema cardiovascular é que chamam mais a atenção. A produção local (tecidual) de todos os elementos do SRA no coração, desde a formação do angiotensinogênio até moléculas inativas como a Angio I-IX, e a descoberta de receptores AT1 e AT2 na membrana nuclear da célula cardíaca, denotam a importância desse sistema para as funções do coração ${ }^{18}$. Por exemplo, a descoberta desses receptores na membrana nuclear aventa a hipótese mecanicista de que a Angio II ao se ligar a receptores AT1 pode induzir alterações na transcrição de genes cardíacos, indicando que a Angio II atue através de receptores intracelulares para regular o crescimento de cardiomiócitos e induzir a hipertrofia cardíaca.

Corroborando com essa ideia, Reudelhuber et al. $\underline{\text { 11 }}$ apontam que o aumento da expressão de AT1 é um estímulo mais potente ao remodelamento miocárdico do que a elevação acentuada da Angio II, sugerindo que a densidade de AT1 pode ser o fator limitante para a hipertrofia cardíaca provocada pela Angio II.
A hipertrofia cardíaca, mediada pelo SRA sistêmico e tecidual, é essencial para o balanço da manutenção da massa cardíaca frente a diversos intervenientes fisiológicos e patológicos, extrínsecos e intrínsecos, como o exercício físico, a caquexia cardíaca e a HAS.

Pensando no espectro patológico, a ativação crônica do receptor AT1 pela Angio II favorece o aparecimento da HAS, de arritmias cardíaca, de acidente vascular cerebral, a proliferação de fibroblastos intramiocárdicos e distúrbios metabólicos como Diabetes Mellitus e Dislipidemia ${ }^{20}$. Já no aspecto fisiológico, a produção de Angio II tecidual pelos cardiomiócitos, frente à elevação da pré-carga cardíaca durante o exercício físico, promove aumento da contratilidade miocárdica, importante para o incremento do inotropismo cardíaco em esforços de moderada a alta intensidade ${ }^{22}$.

Fica evidente que as ações da Angio II são essenciais à conservação da função básica do sistema cardiovascular, que é a homeostasia corporal através da manutenção adequada do fluxo sanguíneo aos diversos tecidos corporais, em repouso ou esforço físico. O estado de doença é causado pelo desequilíbrio das ações da Angio II ao se ligar aos receptores AT1. Esse desequilíbrio é provocado por diversos fatores, dos quais se destaca a inflamação oriunda, por exemplo, de alterações metabólicas (Diabetes Melittus, dislipidemia e obesidade), vasculares (HAS) e tabagismo ${ }^{20}$.

Observe outro ponto interessante, o da retroalimentação positiva da inflamação em diabéticos. Pacientes com desequilíbrio na homeostase do SRA apresentam diminuição da sensibilidade à insulina. Estudos em ratos demostraram que a ativação do receptor AT1 pela Angio II dificulta a sinalização da insulina desencadeando a médio e longo prazo resistência à insulina ${ }^{23}$. Normalmente, a ligação da insulina ao seu receptor fosforila a tirosina e ativa a fosfatidilinositol-3 quinase (PI3K). Em células endoteliais de veias umbilicais humanas, a Angio II prejudicou o acoplamento da insulina a seu receptor e também aumentou a fosforilação da serina, mecanismo que, em células musculares esqueléticas, interfere na sinalização da insulina e consequente translocação do Glut4 do citosol para a membrana ${ }^{24}$. Portanto, o desequilíbrio do SRA pode induzir a Diabetes Mellitus, o que por sua vez eleva a inflamação e retroalimenta a atividade do SRA, retroalimentação positiva de um ciclo efetivamente patogênico. 
No sistema nervoso central, a ligação da Angio II a receptores AT1 estimula, nos neurônios magnocelulares do hipotálamo, a produção da vasopressina (hormônio antidiurético), que gera vasoconstrição arterial ao se ligar a receptores do endotélio vascular arterial, e a reabsorção de $\mathrm{H} 2 \mathrm{O}$ livre de sódio pelos túbulos renais distais. Ambos efeitos favorecem a balança da elevação da PA. Ainda, no sistema nervoso central, a Angio II eleva o tônus autônomo simpático ao interagir com AT1, aumentando a liberação de catecolaminas, especialmente noradrenalina, pelas terminações nervosas periféricas ${ }^{25}$, mecanismo que favorece o surgimento de arritmias.

Nas glândulas suprarrenais a Angio II estimula a produção de catecolaminas, a adrenalina e a noradrenalina. Especificamente, a produção elevada de adrenalina suprarrenal estimula o incremento agudo e crônico da PA, já que a adrenalina, ao se ligar a receptores a-adrenérgicos endoteliais das artérias, favorece fortemente a vasoconstrição. Esse mecanismo é muitas vezes observado em pacientes com HAS crônica ${ }^{26}$.

Finalmente, é imperativo abordar a atuação da Angio Il na carcinogênese. A proliferação celular e a angiogênese reguladas pelo receptor AT1 têm implicações poderosas sobre os tumores cancerígenos. A produção tecidual de Angio ll é um estímulo pró-angiogênico no microambiente tumoral. Tumores implantados em camundongos desenvolveram angiogênese intensiva com indução de fator de crescimento endotelial vascular (VEGF) no estroma do tumor. A produção de fatores angiogênicos, induzidos pela Angio II, envolve a via de sinalização do receptor AT1. Portanto, a utilização de inibidores dos receptores AT1 como os fármacos que bloqueiam AT1 pode ser uma terapêutica efetiva contra o crescimento tumoral27. É também de conhecimento que a Angio II desempenha papel no crescimento e na quimiorresistência das células cancerígenas do pâncreas, positivas para receptores AT1, por sua ação como uma potente molécula mitógena e antiapoptótica ${ }^{9}$. Ademais, foi relatado a ação da Angio II sobre diversos outros tipos de câncer como o carcinoma hepático, de mama e próstata⿳⺈.
O papel fisiológico do receptor AT2 é no mínimo controverso. Expresso principalmente nos tecidos fetais, reduz sua presença nos tecidos com o avançar da idade. Em adultos, se restringe a alguns órgãos, como rins, cérebro, coração, tecido adiposo, células adrenais, pele, miométrio e ovário ${ }^{8}$. Os receptores AT2 são re-expressos durante situações como lesão cardíaca e vascular (infarto do miocárdio, hipertrofia concêntrica ventricular esquerda e proliferação vascular da musculatura lisa), em lesões de nervos periféricos e em substancias depleções de sódio de maneira crônica. O conhecimento da alta expressão desse receptor na vida intrauterina e sua re-expressão em adultos que sofrem lesão tecidual sugerem um forte efeito ponderativo na estruturação e restruturação tecidual? . Corroborando com essa ideia, o polimorfismo do gene que codifica AT2 provoca anomalias congênitas do trato urinário em humanos, reforçando sua importância no desenvolvimento de órgãos e sistemas como o urinário $\stackrel{28}{ }$.

Apesar de todos esses efeitos benéficos, a expressão dos receptores AT2 e sua interação com a Angio Il está associada a situações como hipertrofia concêntrica e apoptose de cardiomiócitos, apoptose de células pancreáticas, do tecido adiposo e neural, por exemplo, da região hipotalâmicạ. Existem, também, evidências de que os receptores AT2 medeiam a dor nociceptiva. Fármacos que inibem os receptores AT2 neurais estão sendo estudados com intuito de reduzir a dor nociceptiva ${ }^{29}$. As ações aparentemente controversas da Angio II, ao interagirem com receptores AT2, exibirão ainda desdobramentos que possivelmente irão repercutir, na ciência e na prática clínica, de forma contundente nos próximos anos.

As Figuras 1 e 2 resumem o SRA e as principais implicações fisiológicas desencadeadas pelas angiotensinas ativas. Para melhor visualização, na Figura 1, as angiotensinas são destacadas em negrito e o angiotensinogênio (considerado o início do SRA) é destacado em vermelho. 


\section{Interação entre o Sistema Renina Angiotensina e a SARS-CoV-2}

Como dito inicialmente, o receptor funcional da SARS-CoV-2 é a ECA 2. Embora se saiba que o RNAm da ECA 2 está presente em praticamente todos os órgãos, inicialmente sua expressão foi descrita no endotélio arterial das coronárias e vasos intra-renais, sendo produzida também de forma local por células cardíacas, renais, testiculares e musculares lisas ${ }^{6}$. No entanto, um importante estudo produzido por Hamming et al. ${ }^{30}$, no qual foram avaliados 93 indivíduos, identificou grande expressão superficial da ECA 2 nas células epiteliais alveolares pulmonares (especialmente as do Tipo II) e enterócitos do intestino delgado. Os autores demonstraram que a ECA 2 é expressa de forma superficial e abundante, em humanos, nos epitélios do pulmão e do intestino delgado, o que pode fornecer potenciais vias de entrada para o SARS-CoV e atualmente para a SARSCoV-2, já que essas células mantêm contato direto com o ambiente externo. Isso explica por que a principal forma de contagio é através de gotículas de saliva dispersas no ar que podem adentrar as vias aéreas respiratórias, e também através da mão contaminada em contato com as narinas ${ }^{30}$. Poderíamos nos perguntar: por que não há relatos de contágio via oral se a presença de ECA 2 é abundante no intestino? A hipótese é de que o $\mathrm{PH}$ ácido do sistema digestório inutilize a ação viral.

A entrada viral inicial pode causar alterações cito patológicas na interface alvéolo-capilar. Na SARS-CoV-2, a expressão abundante de ECA 2 nas células alveolares do tipo II, responsáveis pela produção do surfactante que evita o colapso alveolar, propicia base rápida para expansão viral e um círculo vicioso de destruição da parede alveolar difuso e progressivo. Esse mecanismo explica porquê indivíduos com enfermidades pulmonares infectados pela SARS-CoV-2 apresentam maior complicação clínica e mortalidade.
Nesse contexto, um aspecto curioso é o tabagismo. Existe um racional fisiopatológico que nos induz a pensar numa forte associação entre o tabagismo e a SARS-CoV-2. Na SARS-CoV-2, a alteração na proteína $S$ apresenta afinidade 10 a 20 vezes maior pela ECA 2 que na SARS-CoV 34 . Como a fumaça do cigarro aumenta a expressão da ECA 2 nos pneumócitos tipo 2 e macrófagos alveolares ${ }^{35}$, é plausível imaginar que tabagistas apresentem maior probabilidade de serem infectados e de apresentarem estágios mais avançados da doença. Porém, os trabalhos publicados até então não ratificam essa associação. No estu-

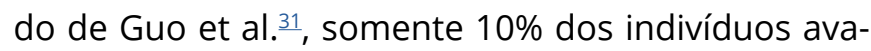
liados que desenvolveram estágio IV ou evoluíram para morte (estágio V) eram fumantes. No estudo de Wu e McGoogan 32 , foi relatado que $50 \%$ dos homens, porém somente 3\% das mulheres, que apresentaram estágios mais avançados da enfermidade (IV e V) eram tabagistas. Ainda nessa linha de pensamento, Zhang et al. $\frac{33}{}$, em uma pesquisa com 140 pessoas que foram hospitalizadas por maior gravidade da doença, identificaram que apenas $6,4 \%$ dos pacientes eram fumantes. Portanto, apesar de alguns cientistas apontarem que o tabagismo facilita a carga viral intermediada pela ECA $2 \frac{36}{6}$, os dados aqui apresentados nos deixam dúvida se o tabagismo é realmente um fator de agravamento da SARS-CoV-2.

A característica espectral da SARS-CoV-2 não depende somente da concentração de ECA 2 nas vias aéreas respiratórias e da condição respiratória do indivíduo infectado. Outro fato a se destacar é que a SARS-CoV-2, ao se ligar à ECA 2 através de seu domínio proteico $S$ (Spike), para se replicar e ter acesso as células corporais, inativa a ECA 2. Como já elucidado neste artigo, a atividade da ECA 2 no SRA favorece a balança de redução da PA, ao atuar sobre a transformação da Angio I em Angio I-IX e da Angio II em Angio I-IX ou em Angio I-VII. Imai et al. $\frac{36}{}$ realizaram um estudo no qual foi induzida lesão pulmonar aguda por aspiração ácida em ratos com e sem deleção da ECA 2. Como resultados, os autores observaram que nos ratos com deleção da ECA 2, além de edema 
pulmonar maciço, apresentaram aumento de $14 \%$ da permeabilidade vascular capilar pulmonar, aumento de $26 \%$ da infiltração de células inflamatórias, diminuição de 33\% da hematose e aumento de aproximadamente 52\% na concentração de Angio II nos pulmões, em comparação aos ratos com lesão pulmonar aguda, mas sem deleção da ECA 2. A lesão pulmonar aguda causada por processos infecciosos aumenta a elastância pulmonar, dificultando a mecânica ventilatória e a hematose. Nos ratos em que foi induzida a lesão pulmonar aguda sem deleção da ECA 2, a elestância pulmonar aumentou 90\% em comparação ao grupo controle sem lesão pulmonar, enquanto nos ratos com lesão respiratória aguda e deleção da ECA 2 o aumento foi de $200 \%$ em comparação ao controle. Dessa forma, os autores concluíram que a lesão pulmonar aguda resulta em diminuição da expressão de ECA 2 e que, ao contrário da ECA 2, a ECA 1 favorece a patogênese da doença através do aumento da produção de Angio II.

Fica claro que a lesão pulmonar provocada pela SARSCoV-2, associada à inativação da ECA 2 e consequente aumento da atividade da ECA 1, aumenta a concentração de Angio II e desencadeia uma retroalimentação positiva de toda patogênese provocada pela infecção. Ademais, em condições normais, 80\% da bradicinina produzida pelo endotélio vascular arterial é inativada nos pulmões pela ECA 1. Na condição provocada pela SARS-CoV-2, a inativação da bradicinina pode ser ainda maior, o que favorece a broncoconstrição e piora o quadro clínico.

Ainda, nessa perspectiva, os pulmões expressam os receptores AT1a e AT2. A inativação da ECA 2 aumenta o estímulo dos receptores AT1 a, os quais, ao interagir com a Angio II, propiciam a lesão pulmonar ${ }^{36}$. Diante dessa explicação, é plausível pensar que fármacos como os antagonistas dos receptores AT1, como também dos inibidores da ECA 1, poderiam beneficiar os pacientes com SARS-CoV-2, porém, nenhum estudo referiu benefício ou malefício do uso desses fármacos ${ }^{37}$. Em suma, levantamos a hipótese de que ao inativar a ECA 2, a SARS-CoV-2 estimula a maior atividade e expressão de ECA 1, dos receptores AT1a e de Angio II, moléculas do SRA que favorecem a evolução da enfermidade e pioram o prognóstico dos pacientes infectados. Vale ressaltar que tais indagações podem ser elucidadas pelo Ensaio clinico Randomizado que está sendo desenvolvido pela Universidade de Minnesota (ClinicalTrials.gov número, NCT04287686.). O estudo tem intenção de investigar os efeitos da losartana na terapêutica para SARS-CoV-2, elaborado por dois grupos de pacientes que receberam previamente tratamento com inibidor de SRAA e estão internados (NCT04312009.) ou não (NCT04311177.) ${ }^{38}$.

Nesse ponto, não podemos duvidar do papel da inflamação nessa interação entre SARS-CoV-2 e SRA. Como já dito anteriormente, a inflamação é um dos substratos que retroalimentam positivamente o SRA, ao provocar, por exemplo, disfunção da parede endotelial vascular arterial, aumentando a atividade dos principais elementos da balança favorável a elevação da $P A^{9,11}$. Ao mesmo tempo, a infecção viral que desencadeia lesão tecidual retroalimenta o processo inflamatório e assim cria um terreno fértil para sua propagação. Não obstante, indivíduos que apresentam condições favoráveis à inflamação têm maior susceptibilidade à instalação da SARS-CoV-2. Talvez não seja coincidente que pessoas com HAS (32\%), Diabetes Mellitus (15\%) e Doença Arterial Coronariana (11\%) sejam as que apresentam maior agressividade da doença, representando $73 \%$ dos que evoluem para morte ${ }^{31}$. Indivíduos hipertensos, diabéticos ou com doença coronariana são os que com frequência exibem marcadores inflamatórios aumentados e, consequentemente, alimentam o ciclo Enfermidade $\rightarrow \uparrow$ SRA $\rightarrow$ Enfermidade, tendo como subsídio de retroalimentação a inflamação 39,40 .

Corroborando com essa ideia, o estudo de Guo et al. ${ }^{31}$ demonstrou correlação linear positiva elevada entre proteína $C$ reativa e os níveis de peptídeo natriurético pró-cerebral N-terminal (NT-proBNP), um importante marcador de disfunção e injuria cardíaca. Adicione a esse ciclo o conhecimento de que a inflamação diminui a reserva imunológica ${ }^{41}$ e teremos então todos os subsídios para instalação e a agressividade da SARS-CoV-2. A Figura 3 representa em forma esquemática esse ciclo. 
Figura 3. Ciclo Inflamação, Enfermidade, Sistema Renina-Angiotensina (SRA). A SARS-CoV-2 se beneficia desse ciclo em pacientes com Hipertensão Arterial Sistêmica (HAS), Diabetes Mellitus (DM) e Doença Arterial Coronariana (DAC) para se instalar e disseminar no corpo do hospedeiro. Esse é um dos mecanismos que explica a agressividade da SARS-CoV-2

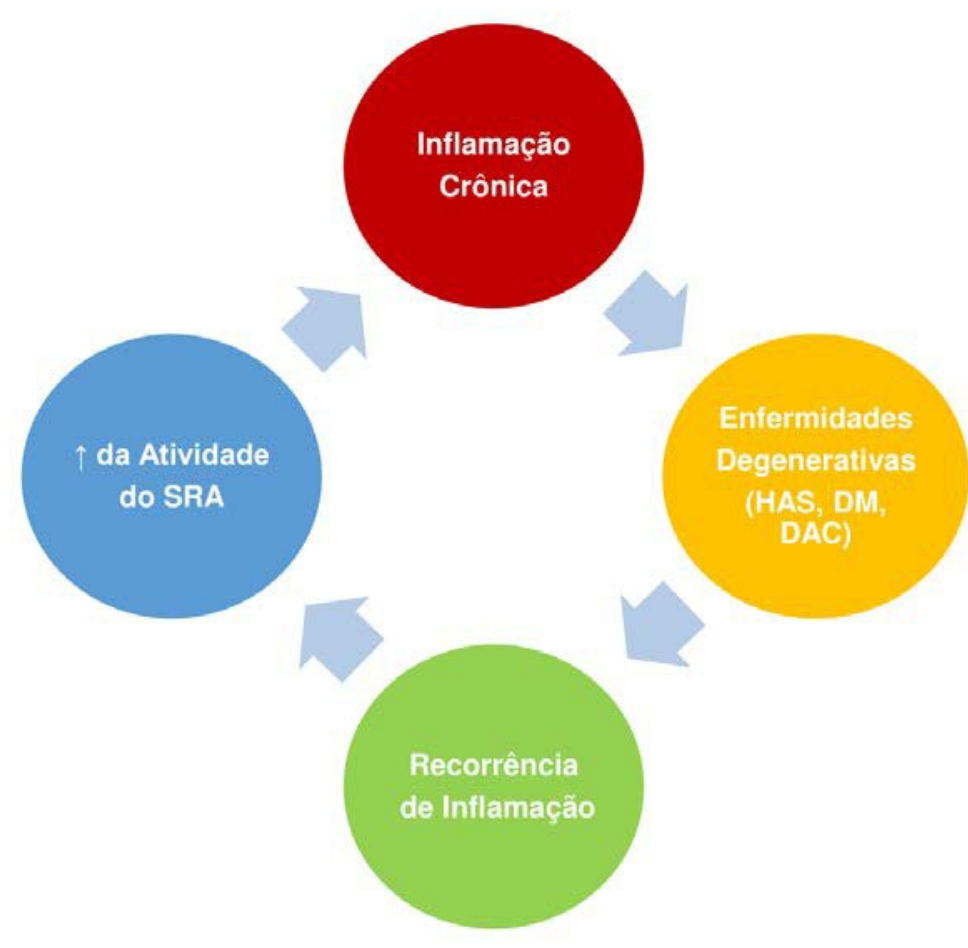

A alta prevalência de enfermidades cardíacas prévias em pessoas que evoluem para óbito na SARS-CoV-2 possivelmente tenha outra associação com o SRA. A presença de um SRA completo nas células cardíacas e vasos coronarianos parece ser um campo extremamente fértil para a atuação da SARS-CoV-2. É possível que, embora isso não tenha sido aventado em nenhum estudo mecanicista sobre a doença, exista facilidade de penetração do vírus no tecido cardíaco e vasos arteriais coronarianos pela presença abundante de ECA 2. Uma vez dentro da célula cardíaca, a SARS-CoV-2 provoca inativação da ECA 2, o que, por consequência, favorece a expressão e atividade da Angio II, da ECA 1 e dos receptores AT1, com consequente diminuição da produção da Angio I-VII e da atividade dos receptores AT1-7 e AT2. Em conjunto, esse desequilíbrio do SRA propicia o desencadeamento de arritmias como a taquicardia e a fibrilação ventricular, a miocardite por intensa atividade inflamatória associada a lesão miocárdica com consequente rebaixamento da função sistólica e proliferação de fibroblastos intramiocárdicos, quadro esse relatado em vários estudos ${ }^{31-33}$. Como o desfecho do estudo de TRED-HF com doentes assintomáticos e portadores de insuficiência cardíaca com fração de ejeção do ventrículo esquerdo recuperada, suspensa as doses da medicação (incluindo os inibidores do SRAA) acarretava em novos episódios da cardiopatia dilatada ${ }^{42}$.

Ainda, muitos pacientes infectados que foram a óbito tiveram infarto do miocárdio provocado por espasmo coronariano ou por aumento da atividade trombogênica endotelial coronariana e/ou desestabilização da placa aterosclerótica pré-existente ${ }^{31,43}$. Revisitando o SRA explicitado neste artigo, fica elucidativo o entendimento do porquê isso acontece. Como descrito anteriormente, o desequilíbrio do SRA com diminuição da produção da Angio I-VII e consequente aumento da produção de Angio II favorece a balança pró-trombogênica e inflamatória 111,14,18,20-23,25,28, 0 que explica o desfecho de infarto do miocárdio em pacientes que evoluíram para os estágios IV e V da SARS-CoV-2.

Levantamos também outra hipótese, a de que a produção tecidual do SRA dita quais são os principais órgãos alvo da SARS-CoV-2. Ela é reforçada por outro achado dos artigos que descrevem as características dos pacientes que foram contaminados e hospitalizados. No estudo de Guo et al. ${ }^{31}$, apenas 3\% dos 187 pacientes estudados apresentavam inicialmente doença renal, sendo que durante o período de hospitalização $14 \%$ desenvolveram doença renal. Contudo, a predominância é mais elevada entre doentes $\operatorname{críticos}^{44}$. 
Como já mencionado, os rins também exibem produção local completa do SRA. A presença de doença renal parece não favorecer a instalação da SARSCoV-2 mas sim, se apresenta como resultado dela. Nos rins, a diminuição da atividade da ECA 2 nas artérias renais pode provocar vasoconstrição e redução do fluxo nas arteríolas aferentes, levando a aumento da produção da renina e consequentemente de todo o SRA sistêmico.

No entanto, mesmo frente a toda essa contextualização da interação entre SARS-CoV-2 e SRA, a característica multifacetada do SARS-CoV-2 gera perguntas que atualmente ainda não foram respondidas, como o quanto o comprometimento hepático agudo decorrente da infecção viral retroalimenta positivamente o SRA e a própria SARS-CoV-2, como relatado também no estudo de Guo et al. ${ }^{31} \mathrm{~A}$ inexistência de levantamentos sobre a presença prévia da síndrome da apneia/hipopneia obstrutiva do sono nos pacientes mais graves pode ser uma característica subvalorizada dos pacientes com SARS-CoV-2, já que ela se associa fortemente à HAS, às doenças cardiovasculares, à elevação da atividade do SRA e à inflamação. Mais especificamente sabemos que existe quantidade significativa de receptores AT1 no seio carotídeo. A maior produção endotelial de Angio II induz aumento da atividade dos quimiorreceptores periféricos localizados nessa região. Como consequência há aumento da atividade simpática e consequente elevação da inflamação, do trabalho cardíaco (elevação da frequência cardíaca e da contratilidade miocárdica), da ventilação e da resistência periférica total (vasoconstrição). O despertar dessa cascata se inicia com a hipóxia intermitente oriunda da síndrome da apneia/hipopineia durante o sono ${ }^{45}$. Portanto, nos parece muito lógico que pessoas portadoras dessa síndrome apresentem pior evolução clínica quando infectadas. No entanto, isso ainda foi pouco explorado pela literatura.

Outro ponto, por que não há relatos de indivíduos com Síndrome da Imuno-Deficiência-Adquirida contaminados com SARS-CoV-2, já que essa doença afeta drasticamente a defesa imunológica e é causa de inflamação crônica elevada? Possivelmente os futuros estudos nos ajudarão a responder essas questões e a entender ainda melhor a interação entre a SARSCoV-2 e o SRA.

\section{Conclusão}

Baseado nos estudos mecanicistas e de descrição clínica da SARS-CoV-2, é possível traçar fortes e diversas interações entre o sistema renina angiotensina e a SARS-CoV-2. No entanto, a elucidação dessas interações ainda não fornecem todas as respostas às indagações e achados que permeiam essa pandemia. A característica espectral da SARS-CoV-2 e sua interação com o sistema renina angiotensina ainda será um terreno farto para investigações científicas futuras.

\section{Contribuições dos autores}

Petto J participou da concepção, delineamento, busca, interpretação de resultados e redação do artigo científico. Santos PHS participou da busca, interpretação dos resultados e redação do artigo científico. Santos LFS e Sena DSS participaram da busca e redação do artigo científico. Sacramento MS participou da busca, interpretação dos resultados e redação do artigo científico.

\section{Conflitos de interesses}

Nenhum conflito financeiro, legal ou político envolvendo terceiros (governo, empresas e fundações privadas, etc.) foi declarado para nenhum aspecto do trabalho submetido (incluindo, mas não se limitando a subvenções e financiamentos, participação em conselho consultivo, desenho de estudo, preparação de manuscrito, análise estatística, etc.).

\section{Referências}

1. Ruan Q, Yang K, Wang W, Jiang L, Song J. Clinical predictors of mortality due to COVID-19 based on an analysis of data of 150 patients from Wuhan, China. Intensive Care Med. 2020;46:846-8 https://doi.org/10.1007/s00134-020-05991-x

2. Strabelli TMV, Uip DE. COVID-19 e o Coração. Arq Bras Cardiol. 2020;144(4): 598-600. https://doi.org/10.36660/abc.20200209

3. Zhang J, Litvinova M, Wang W, Wang Y, Deng X, Chen X, et al. Evolving epidemiology and transmission dynamics of coronavirus disease 2019 outside Hubei province, China: a descriptive and modelling study. Lancet Infect. Dis. 2020;20:793-802. https://doi. org/10.1016/S1473-3099(20)30230-9

4. Organização Pan-americana de Saúde. Folha informativa COVID-19 - Escritório da OPAS e da OMS no Brasil [Internet]. Organização Mundial de Saúde; 2020. [atualizado 2021 jan. 14; citado em 2020 nov. 15]. Disponível em: https://www.paho.org/pt/ covid19 
5. The Novel Coronavirus Pneumonia Emergency Response Epidemiology Team. The epidemiological characteristics of an outbreak of 2019 novel coronavirus diseases (COVID-19) in China. Chin J Epidemiol. 2020;17;41(2):145-51. https://doi.org/10.3760/ cma.j.issn.0254-6450.2020.02.003

6. Vickers C, Hales P, Kaushik V, Dick L, Gavin J, Tang J, et al. Hydrolysis of biological peptides by human angiotensinconverting enzyme-related-carboxypeptidase (ACE2). J Biol Chen. 2002;277(17):14838-43. https://doi.org/10.1074/jbc.m200581200

7. Carey RM, Siragy HM. Newly recognized componentes of the renin-angiotensin system: potential roles in cardiovascular and renal regulation. Endocr Rev. 2003;24(3):261-71. https://doi. org/10.1210/er.2003-0001

8. Dzau VJ. Circulating versus local renin-angiotensin system in cardiovascular homeostasis. Circulation. 1998;77(6 Pt 2):14-13. Citado em: PMID: $\underline{3286045}$

9. Karnik SS, Unal H, Kemp JR, Tirupula KC, Eguchi S, Vanderheyden PML, et al. International Union of Basic and Clinical Pharmacology. XCIX. Angiotensin Receptors: Interpreters of Pathophysiological Angiotensinergic Stimulis. Pharmacol Rev. 2015;67(4):754-819. http://doi.org/10.1124/pr.114.010454

10. Atlas AS. The renin angitensin system revisited: classical and nonclassical pathways of angiotensin formation. Mt Sinai J Med. 1998;65(2):87-96. Citado em: PMID: 9520511

11. Campbell DJ. The renin-angiotensin and the kallikrein-kinin system. Int J Biochem Cell Biol. 2003;35(6):784-91. https://doi. org/10.1016/S1357-2725(02)00262-5

12. Fyhrquist F, Saijonmaa O. Renin-angiotensin system revisited. J Intern Med. 2008;264(3):224-36. Citado em: PMID: 18793332

13. Sedeek M, Hebert RL, Ketmedy CR, Burns KD, Touyz RM. Molecular mechanisms of hypertension: role of Nox family NADPH oxidases. Curr Opin Nephrol Hypertens. 2009;18(2):122-7. https://doi.org/10.1097/MNH.0b013e32832923c3

14. Gomes ER, Santos RA, Guatimosim S. Angiotensin-(17)-mediated signaling in cardiomyocytes. Int J Hypertens. 2012;2012:493129. https://doi.org/10.1155/2012/493129

15. Crackower MA, Sarao R, Oudit GY, Yagil C, Kozieradzki I, Scanga SE, et al. Angiotensin -converting enzyme 2 is an essential regulator of heart function. Nature. 2002;417(6891):822-8. https:// doi.org/10.1038/nature00786

16. Donoghue M, Hsieh F, Baronas E, Godbout K, Gosselin M, Stagliano N, et al. A novel angiotensin converting enzyme-related carboxypeptidase (ACE2) converts angiotensin I to angiotensin 1-9. Cir. Res. 2000;87(5):e1-9. https://doi.org/10.1161/01. res.87.5.e1

17. Singh KD, Karnik SS. Angiotensin Receptors: Structure, Function, Signaling and Clinical Applications. J Cell Signal [Internet]. 2016;1(2):111.Disponível em: https://pubmed.ncbi.nlm. nih.gov/27512731/
18. Lochard N, Thibault G, Silversides DW, Touyz RM, Reudelhuber TL. Chronic production of angiotensin IV in the brain leads to hypertension that is reversible with an angiotensin II AT1 receptor antagonist. Circ Res. 2004;94(11):1451-7. https://doi. org/10.1161/01.RES.0000130654.56599.40

19. Tadevosyan A, Maguy A, Villeneuve LR, Babin J, Bonnefoy A, Allen BG, et al. Nuclear-delimited Angiotensin Receptor-mediated Signaling Regulates Cardiomyocyte Gene Expression. J Biol Chem. 2010;16;285(29):22338-49. Citado em: PMID: 20463030

20. Gasparo M, Catt KJ, Inagami T, Wright JW, Unger T. International Union of Pharmacology. XXIII. The angiotensin II receptors. Pharmacol Rev [Internet]. 2000; 52(3):41572. Disponível em: https://pharmrev.aspetjournals.org/ content/52/3/415

21. Reudelhuber TL, Bernstein KE, Delafontaine P. Is angiotensin II a direct mediator of left ventricular hypertrophy? Time for another look. Hypertension. 2007;49(6):1196-201. https://doi.org/10.1161/ HYPERTENSIONAHA.106.075085

22. Mederos y Schnitzler M, Storch U, Gudermann T. AT1 receptors as mechanosensors. Curr Opin Pharmacol. 2011;11(2):112-6. https://doi.org/10.1016/j.coph.2010.11.003

23. Ogihara T, Asano T, Ando K, Chiba Y, Sakoda H, Anai M, et al. Angiotensin II-induced insulin resistance is associated with enhanced insulin signaling. Hypertension. 2002;40(6):872-9. https://doi.org/10.1161/01.hyp.0000040262.48405.a8

24. Andreozzi F, Laratta E, Sciacqua A, Perticone F, Sesti G. Angiotensin II impairs the insulin signaling pathway promoting production of nitric oxide by inducing phosphorylation of insulin receptor substrate-1 on Ser312 and Ser616 in human umbilical vein endothelial cells. Circ Res. 2004;94(9):1211-8. https://doi. org/10.1161/01.res.0000126501.34994.96

25. Ferrario CM, Barnes KL, Block CH, Brosnihan KB, Diz DI, Khosla MC, et al. Pathways of angiotensin formation and function in the brain. Hypertension. 1990;15(supl 2):113-I19. https://doi. org/10.1161/01.hyp.15.2_suppl.i13

26. Hall JE. The renin-angiotensin system: renal actions and blood pressure regulation. Compr Ther. 1991;17(5):8-17. Citado em: PMID: 1879129

27. Fujita M, Hayashi I, Yamashina S, Fukamizu A, Itoman M, Majima M. Angiotensin type 1a receptor signaling-dependent induction of vascular endothelial growth factor in stroma is relevant to tumor-associated angiogenesis and tumor growth. Carcinogenesis. 2005;26(2):271-9. https://doi.org/10.1093/carcin/ bgh324

28. Hohenfellner K, Hunley TE, Schloemer C, Brenner W, Yerkes $\mathrm{E}$, Zepp F, et al. Angiotensin type 2 receptor is important in the normal development of the ureter. Pediatr Nephrol. 1999;13:18791. https://doi.org/10.1007/s004670050589 
29. Smith MT, Woodruff TM, Wyse BD, Muralidharan A, Walther T. A small molecule angiotensin II type 2 receptor $\left(A_{2} R\right)$ antagonist produces analgesia in a rat model of neuropathic pain by inhibition of p38 mitogen-activated protein kinase (MAPK) and p44/p42 MAPK activation in the dorsal root ganglia. Pain Med. 2013;14(10):1557-68. https://doi.org/10.1111/pme.12157

30. Hamming I, TimensW, Bulthuis ML, Lely AT, Navis G, van Goor $\mathrm{H}$. Tissue distribution of ACE2 protein, the functional receptor for SARS coronavirus: a first step in understanding SARS pathogenesis. J Pathol. 2004;203(2):631-7. https://doi.org/10.1002/ path. 1570

31. Guo T, Fan Y, Chen M, Wu X, Zhang L, He T, et al. Association of cardiovascular disease andmyocardial injury with outcomes of patients hospitalized with 2019-coronavirus disease (COVID-19). JAMA Cardiol. 2020;5(7):811-8. https://doi.org/10.1001/ jamacardio.2020.1017

32. Wu Z, McGoogan JM. Characteristics of and important lessons from the coronavirus disease 2019 (COVID-19) outbreak in China: summary of a report of 72314 cases from the Chinese Center for Disease Control and Prevention. JAMA. 2020;323(13):1239-42. https://doi.org/10.1001/jama.2020.2648

33. Zhang J, Dong X, Cao YY, Yuan YD, Yang YB, Yan YQ, et al. Clinical characteristics of 140 patients infected with SARSCoV-2 in Wuhan, China. Allergy. 2020;75(7):1730-41. https://doi. org/10.1111/all.14238

34. The National Center for Biotechnology. NCBI ACE2 Angiotensin I Converting Enzyme 2 [Homo Sapiens (Human)] [Internet]. Estados Unidos: U.S. National Library of Medicine. [atualizado 2020 mar. 05; citado em 2020 jun. 18]. Disponível em: https://www.ncbi.nlm.nih.gov/ gene?Db=gene \&Cmd=DetailsSearch\&Term $=59272$

35. Cai G, Bossé Y, Xiao F, Kheradmand F, Amos Cl. Tobacco Smoking increases the Lung Gene Expression of ACE2, the Receptor of SARS-CoV-2. Am J. Respir. Crit. Care Med. 2020;201(12):1557-9. https://doi.org/10.1164/rccm.2020030693LE

36. Imai Y, Kuba K, Rao S, Huan Y, Guo F, Guan B, et al. Angiotensin-converting enzyme 2 protects from severe acute lung failure. Nature 2005;436:112-6. https://doi.org/10.1038/ nature03712
37. Bozkurt B, Kovacs R, Harrington B. Joint HFSA/ACC/AHA Statement Addresses Concerns Re: Using RAAS Antagonists in COVID-19. J Card Fail. 2020;26(5):370. https://doi.org/10.1016/j. cardfail.2020.04.013

38. Vaduganathan $M$, Vardeny $O$, Michel T, McMurray JJV, Pfeffer MA, Solomon SD. Renin-Angiotensin-Aldosterone System Inhibitors in Patients with Covid-19. N Engl J Med. 2020;382(17):1653-9. https://doi.org/10.1056/NEJMsr2005760

39. Prasad A, Quyyumi AA. Renin-Angiotensin system and angiotensin receptor blockers in the metabolic syndrome. Circulation. 2004;110(11):1507-12. https://doi.org/10.1161/01. CIR.0000141736.76561.78

40. Kim S, Iwao H. Molecular and cellular mechanisms of angiotensin II-mediated cardiovascular and renal diseases. Pharmacol Rev. 2000;52(1):11-34. Citado em: PMID: 10699153

41. Velazquez-Caldelas TE, Alcalá-Corona SA, Espinal-Enríquez J, Hernandez-Lemus E. Unveiling the Link Between Inflammation and Adaptive Immunity in Breast Cancer. Front Immunol. 2019;10:56. https://doi.org/10.3389/fimmu.2019.00056

42. Halliday BP, Wassall R, Lota AS, Khalique Z, John Gregson J, Newsome S, et al. Withdrawal of pharmacological treatment for heart failure in patients with recovered dilated cardiomyopathy (TRED-HF): an open-label, pilot, randomised trial. Lancet. 2019;393(10166):61-73. https://doi.org/10.1016/S01406736(18)32484-X

43. Lu R, Zhao X, Li J, Niu P, Yang B, Wu H, et al. Genomic characterisation and epidemiology of 2019 novel coronavirus: implications for virus origins and receptor binding. Lancet. 2020;395(10224):565-74. https://doi.org/10.1016/S01406736(20)30251-8

44. Arentz M, Yim E, Klaff L, Lokhandwala S, Riedo FX, Chong M, et al. Characteristics and Outcomes of 21 Critically III Patients With COVID-19 in Washington State. JAMA. 2020;323(16):1612-4. https://doi.org/10.1001/jama.2020.4326

45. Fung ML. Expressions of angiotensin and cytokine receptors in the paracrine signaling of the carotid body in hypoxia and sleep apnea. Respir Physiol Neurobiol. 2015;209:6-12. https://doi. org/10.1016/j.resp.2014.09.014 